(D) Check for updates

Cite this: Org. Biomol. Chem., 2019, 17,5943

Received 17th April 2019

Accepted 3rd May 2019

DOI: $10.1039 / c 90 b 00885 c$ rsc.li/obc

\title{
Design of thiazole orange oligonucleotide probes for detection of DNA and RNA by fluorescence and duplex melting $\dagger$
}

\author{
Piotr Klimkowski, ${ }^{a}$ Sara De Ornellas, ${ }^{a, b}$ Daniel Singleton, ${ }^{c}$ Afaf H. El-Sagheer (D) ${ }^{a, d}$ \\ and Tom Brown (iD *a
}

\begin{abstract}
We have synthesised a range of thiazole orange (TO) functionalised oligonucleotides for nucleic acid detection in which TO is attached to the nucleobase or sugar of thymidine. The properties of duplexes between TO-probes and their DNA and RNA targets strongly depend on the length of the linker between TO and the oligonucleotide, the position of attachment of TO to the nucleotide (major or minor groove) and the mode of attachment of thiazole orange (via benzothiazole or quinoline moiety). This information can be used to design probes for detection of target nucleic acids by fluorescence or duplex melting. With cellular imaging in mind we show that 2'-OMe RNA probes with $\mathrm{TO}$ at the 5-position of uracil or the 2 '-position of the ribose sugar are particularly effective, exhibiting up to 44-fold fluorescence enhancement against DNA and RNA, and high duplex stability. Excellent mismatch discrimination is achieved when the mispaired base is located adjacent to the TO-modified nucleotide rather than opposite to it. The simple design, ease of synthesis and favourable properties of these TO probes suggest applications in fluorescent imaging of DNA and RNA in a cellular context.
\end{abstract}

\section{Introduction}

Thiazole orange (TO) is an unsymmetrical cyanine dye which can be conjugated to oligonucleotides (ONs) to create fluorogenic hybridisation probes. ${ }^{1-3}$ TO becomes highly fluorescent upon binding to nucleic acids due to restriction of rotation about the methine bridge, hence TO-ON conjugates have been used for the detection of target nucleic acids. ${ }^{4-10}$ An important property of TO-ON probes is the significant increase in duplex stability imparted by intercalation of the TO moiety. ${ }^{11} \mathrm{~A}$ number of different designs of TO probe systems have been studied (Table S13 $\dagger$ ), for example PNA-based forced intercalation (FIT) probes containing TO have been shown to produce quantum yields $(\Phi)$ up to 0.32 on binding to complementary nucleic acids. ${ }^{3,12}$ A DNA version of FIT probes has been devel-

\footnotetext{
${ }^{a}$ Department of Chemistry, University of Oxford, 12 Mansfield Road, Oxford, OX1 3TA, UK. E-mail: tom.brown@chem.ox.ac.uk

${ }^{b}$ Weatherall Institute of Molecular Medicine, John Radcliffe Hospital, Headley Way, Oxford, OX3 9DS, UK

${ }^{c}$ ATDBio, School of Chemistry University of Southampton, SO17 1BJ, UK

${ }^{d}$ Chemistry Branch, Department of Science and Mathematics, Faculty of Petroleum and Mining Engineering, Suez University, Suez 43721, Egypt

$\dagger$ Electronic supplementary information (ESI) available. See DOI: 10.1039/ c9ob00885c
}

oped in which the quantum yield increases from 0.02 to 0.23 upon target binding, ${ }^{13,14}$ and ECHO probes, containing thymidine modified with two TO units, give low background in the single stranded form and quantum yields up to 0.44 while bound to matched RNA targets. ${ }^{15}$ Investigations on the relationship between the fluorogenic properties of thiazole orange and probe structure have been carried out previously. In a study in which TO was linked to the DNA phosphodiester backbone via its quinoline moiety, differences in fluorescence $\left(F_{\mathrm{ds}} / F_{\mathrm{ss}}\right)$ were moderate; 2.4-fold for the TO-minor groove isomer and 0.8 -fold the major groove isomer. Attachment of TO via its benzothiazole moiety in the major groove gave a 2.7fold increase in fluorescence upon duplex formation and 1.3fold increase when directed into minor groove. ${ }^{7}$ In a study on PNA in which TO was employed as a surrogate base the fluorescence increase upon duplex formation was large (26-fold) when TO was attached by its quinoline moiety, but was small when it was attached by its benzothiazole moiety. ${ }^{16}$

Recently we described a novel fluorogenic probe system (combination probes) that contains a nucleotide modified with both TO and a FRET-compatible second dye. ${ }^{17}$ This study, along with an awareness of the numerous potential diagnostic applications, prompted us to examine the properties of thiazole orange oligonucleotides in more detail with the aim of developing effective TO-probes that are simple to synthesise. 


\section{Material and methods}

\section{TO-NHS ester labelling $(\operatorname{method} 1)$}

To a solution of thiazole orange $\mathrm{TO}_{\mathrm{Q} / \mathrm{B} 6}(20$ eq.) in $\mathrm{DMF}$ $(120 \mu \mathrm{L}), \mathrm{DSC}^{18,19}$ or PyBop ${ }^{20}$ (20 eq.) and NMM (60 eq.) were added and the mixture was shaken for $30 \mathrm{~min}$ at $30^{\circ} \mathrm{C}$ (DSC) or $10 \mathrm{~min}$ at $37^{\circ} \mathrm{C}(\mathrm{PyBOP})$ at $400 \mathrm{rpm}$. The mixture was added to an equal volume of the amino-modified oligonucleotide (200 nmol, 1.0 eq.) dissolved in carbonate buffer $\left(\mathrm{NaHCO}_{3} /\right.$ $\left.\mathrm{Na}_{2} \mathrm{CO}_{3}, 0.5 \mathrm{M}, \mathrm{pH}=8.75\right)$ in an Eppendorf tube and shaken for $4 \mathrm{~h}$ at $37^{\circ} \mathrm{C}$. The mixture was desalted by NAP gel filtration column and purified by RP-HPLC to obtain desired pure labelled oligonucleotide, isolated yields with DSC were $40-50 \%$, and with PyBop were $50-70 \%$. Preparation of the amino-modified oligonucleotides is described in the ESI $\dagger$ and a summary of all oligonucleotide sequences is in Tables S1 and $\mathrm{S} 2 . \dagger$

PyBOP was found to give higher coupling efficiencies (conversion calculated by crude HPLC chromatograms at $260 \mathrm{~nm}$ after gel filtration, Fig. S2 $\dagger$ ) and higher isolated yields (amount of nmol obtained after HPLC purification) than DSC.

\section{TO-NHS ester labelling (method 2$)$}

A solution of thiazole orange $\mathrm{TO}_{\mathrm{Q} / \mathrm{B} 6}$ NHS ester (5 eq.) in DMF $(80 \mu \mathrm{L})$ was added to an oligonucleotide $(200 \mathrm{nmol})$ dissolved in carbonate buffer $\left(\mathrm{NaHCO}_{3} / \mathrm{Na}_{2} \mathrm{CO}_{3}, 0.5 \mathrm{M}, \mathrm{pH}=8.75\right.$, $120 \mu \mathrm{L}$ ) and shaken for $5 \mathrm{~min}$ at $20{ }^{\circ} \mathrm{C}$. The mixture was desalted by NAP gel filtration column and purified by RP-HPLC to obtain the desired labelled oligonucleotide. Complete conversion to the product was observed by HPLC, and isolated yields were $60-75 \%$ (Fig. S3 $\dagger$ ).

\section{Results and discussion}

\section{Thiazole orange probe design and synthesis}

Detection and imaging of cellular DNA and RNA are increasingly important fields of study ${ }^{21,22}$ and fluorogenic intercalators are potentially valuable in this context. Hence we undertook investigations on the fluorescent and duplex stabilising properties of a number of TO probe designs. For synthetic convenience we focused on attachment of thiazole orange to the thymidine nucleotide, but linking it to other nucleotides should also be feasible. ON probes can be modified with TO at their nucleobase, ribose sugar or the phosphodiester backbone. ${ }^{23}$ Another key variable is the position on thiazole orange where the linker between TO and the probe is attached; this can be via its benzothiazole or quinoline nitrogen. ${ }^{2,7}$ In order to investigate the effects of these alternative modes of attachment on fluorescence and duplex stability, three nucleoside monomers, 5-propargylamino-dT (PA), amino-C6-dT (C6) and 2'-aminoethoxy-T (AE) were used to introduce TO into oligonucleotides by labelling their aliphatic amino groups (Fig. 1). To achieve this, thiazole orange was functionalised with a hexanoic or decanoic acid linker on either the benzothiazole $\left(\mathrm{TO}_{\mathrm{B} 6} /\right.$ $\left.\mathrm{TO}_{\mathrm{B} 10}\right)$ or the quinoline moiety $\left(\mathrm{TO}_{\mathrm{Q6}} / \mathrm{TO}_{\mathrm{Q} 10}\right)$. In nucleic acid
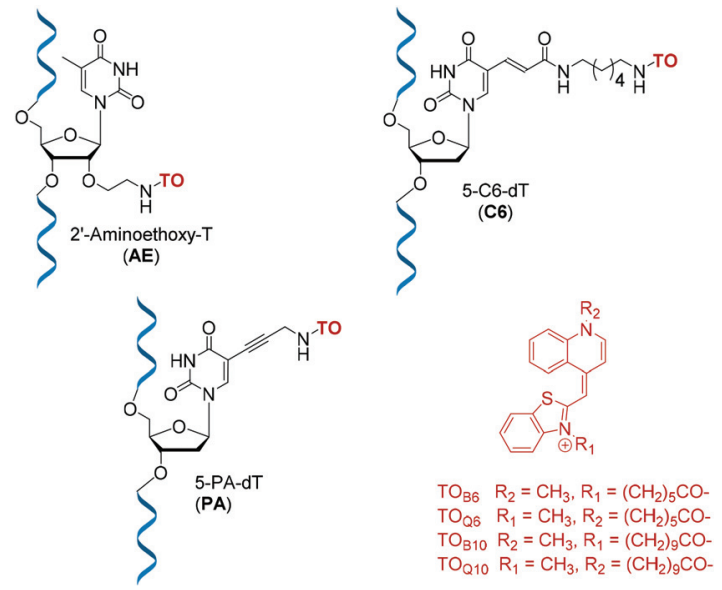

Fig. 1 Structures of TO-modified nucleotides AE, C6, PA and the TO moieties used as carboxylic acids or NHS esters for oligonucleotide labelling.

duplexes PA and C6 locate the TO dye in the vicinity of the major groove, ${ }^{24}$ while $\mathrm{AE}$ positions it in the minor groove region, thereby providing structural diversity. ${ }^{25}$

The phosphoramidite monomers of PA and AE, were synthesised according to published procedures, ${ }^{26-28}$ and C6 phosphoramidite (amino-C6-dT) was purchased from Glen Research. All three monomers were incorporated into a series of 10-mer oligonucleotides (ONs), which were post-synthetically labelled with $\mathrm{TO}_{\mathrm{B} 6}$ or $\mathrm{TO}_{\mathrm{Q} 6}$ in high yield using (benzotriazol-1-yloxy)tripyrrolidinophosphonium hexafluorophosphate (PyBOP) and $N$-methylmorpholine (NMM) in DMF. ${ }^{29}$ PyBOP was found to give superior yields to previously reported coupling methods which employed $N, N^{\prime}$-disuccinimidyl carbonate (DSC), the reaction being complete in 4 hours (Fig. S2†). ${ }^{30,31}$ An optimised labelling procedure using the NHS esters of $\mathrm{TO}_{\mathrm{B} 6}$ or $\mathrm{TO}_{\mathrm{Q} 6}$ remarkably gave almost $100 \%$ conversion to product in just 5 minutes (Fig. S3†). These highly efficient coupling strategies were also successful in a more challenging case; the synthesis of probes with double additions of TO (Table S $2 \dagger$ ).

\section{DNA duplex stabilisation by TO-ODN probes}

To identify the effects of base stacking on TO fluorescence and duplex stabilisation, four different ODNs sequences were synthesised with varied base sequence around the TO-modified nucleotide (Table 1A, Table S3†). Addition of TO increased duplex stability (melting temperature, $T_{\mathrm{m}}$ ) to quite varying degrees when the ODNs were hybridised to fully complementary DNA strands $\left(\Delta T_{\mathrm{m}}=+1.3\right.$ to $\left.14.6^{\circ} \mathrm{C}\right)$ as previously reported in different probe systems. ${ }^{4,32}$ In the major groove (the 5-position of the thymine nucleobase), the $\mathrm{TO}_{\mathrm{B} 6}$ modification is more stabilising and the short linker (PA) is more effective than the long linker (C6). In the minor groove (2'-position of the sugar, $\mathrm{AE}) \mathrm{TO}_{\mathrm{B} 6}$ and $\mathrm{TO}_{\mathrm{Q} 6}$ have similar stabilising effects. In general, a combination of $\mathrm{PA}$ with $\mathrm{TO}_{\mathrm{B} 6}$ gave the best $\Delta T_{\mathrm{m}}$. There are some strong sequence-dependent effects. Most 
Table 1 Changes in melting temperature $\left(\Delta T_{m}\right)$ for DNA duplexes formed by TO-labelled ODN1-4 (A) and changes in fluorescence emission $\left(F_{\mathrm{ds}} /\right.$ $F_{\mathrm{ss}}$ ) before and after formation of matched and mismatched DNA duplexes (B). $T_{\mathrm{m}}, F_{\mathrm{ss}}, F_{\mathrm{ds}}$ were obtained in a buffer containing $10 \mathrm{mM}$ phosphate $200 \mathrm{mM} \mathrm{NaCl}$ at pH 7.0. DNA concentrations for $T_{\mathrm{m}}$ studies were $3.0 \mu \mathrm{M}$ of ODN1-4 and $3.3 \mu \mathrm{M}$ of target strand. For $F_{\mathrm{ds}} / F_{\mathrm{ss}} 0.25 \mu \mathrm{M}$ of ODN1-4 and $0.28 \mu \mathrm{M}$ of target were used. $T_{\mathrm{m}}$ values are an average of 4 measurements, fluorescence data were measured at least as a duplicate. TO $\mathrm{Q}_{\mathrm{B} 6}: \lambda_{\mathrm{ex}}$ $=484 \mathrm{~nm}, \lambda_{\mathrm{em}}=510 \mathrm{~nm}$, slit ex $=7 \mathrm{~nm}$, slit em $=7 \mathrm{~nm}$ at $20^{\circ} \mathrm{C}$

$1 \mathrm{~A}$

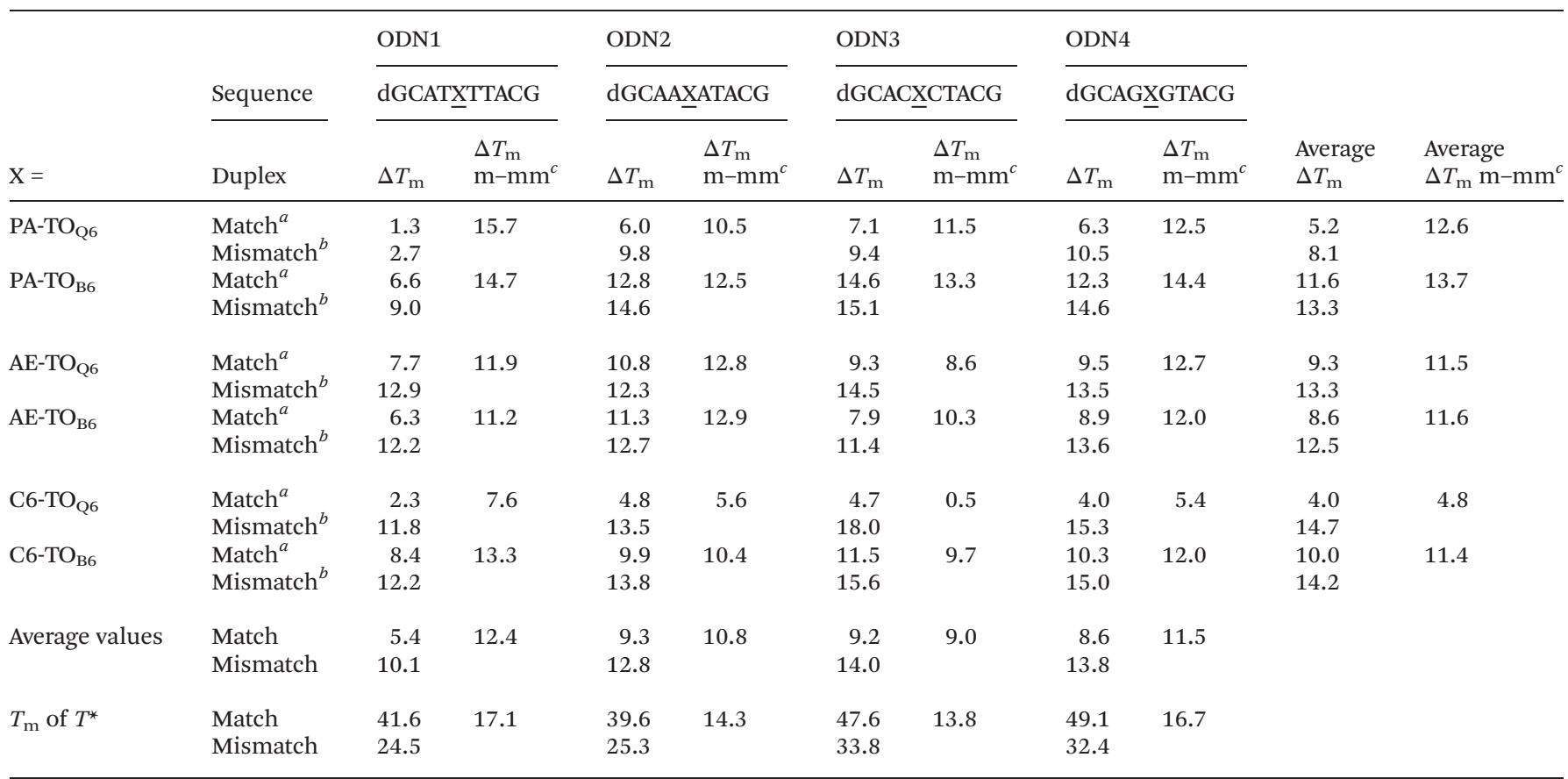

$1 \mathrm{~B}$

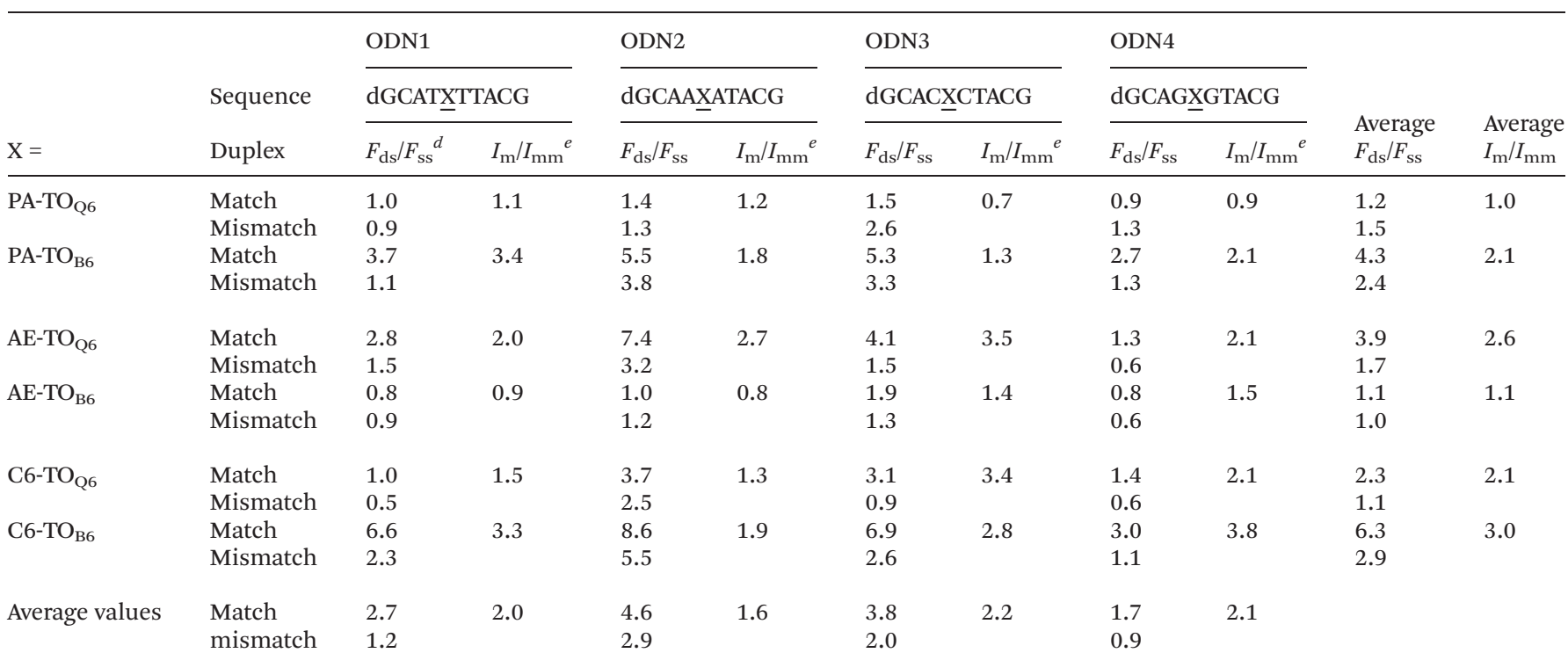

${ }^{a}$ In comparison to the matched unmodified duplex. ${ }^{b}$ In comparison to the mismatched unmodified duplex. ${ }^{c}$ Difference between $T_{\mathrm{m}}$ of matched (m) and mismatched $(\mathrm{mm})$ target in ${ }^{\circ} \mathrm{C},{ }^{*}=T_{\mathrm{m}}$ value of unmodified matched and mismatched duplexes. ${ }^{d}$ Ratio of integrated fluorescence intensity for $F_{\mathrm{ds}}$ and $F_{\mathrm{ss}}$ of ODN probes with matched or mismatched targets. ${ }^{e}$ Ratio of fluorescence intensity of matched $\left(I_{\mathrm{m}}\right)$ and mismatched $\left(I_{\mathrm{mm}}\right)$ intensity of probes-targets duplexes at $\lambda_{\mathrm{em}}$ max.

notably, in fully matched DNA duplexes, placing the TO-modified nucleotide between thymine bases (TXT) gives the least stable duplexes, whereas the other stacking environments are significantly more stabilising and are similar to each other.
The TO-modified ODNs were also evaluated in mismatched duplexes by replacing the adenine base opposite to the TOmodified $\mathrm{T}$ with thymine to create a $\mathrm{T}: \mathrm{T}$ mismatch directly opposite the TO-T nucleotide. As expected, melting tempera- 
tures were significantly lower than those with the fully complementary strands, $\mathrm{PA}-\mathrm{TO}_{\mathrm{B} 6}$ showing the greatest mismatch discrimination of the series, and the TXT sequence (ODN1) was the most sensitive to the mismatch. This study indicates that thiazole orange does not prevent thermal mismatch discrimination, although it does reduce it relative to unmodified mismatched duplexes. However, locating the mispaired base directly opposite thiazole orange is not the optimum strategy for detection of point mutations or single nucleotide polymorphisms (SNPs). A superior strategy is discussed later.

\section{Fluorescence properties of TO-ODN probes with DNA targets}

Fluorescence emission spectroscopy of the TO-modified ODNs as single strands and with their matched and mismatched complementary DNA strands showed clear trends (Table 1B, Fig. $55 \dagger) .+$ Both the position and mode of attachment of the dye strongly influence the fluorescence properties. C6- $\mathrm{TO}_{\mathrm{B} 6}$ and $\mathrm{PA}^{-} \mathrm{TO}_{\mathrm{B} 6}$ provided good discrimination between single strand (ss) and double strand (ds), and C6 is better than PA with an average 6.3-fold increase in fluorescence on duplex formation. Fluorescence-based mismatch discrimination of TO-ODNs (1-4) against DNA targets was best achieved by PA and $\mathrm{C} 6$ attached to $\mathrm{TO}_{\mathrm{B} 6}$, i.e. with attachment of thiazole orange in the major groove. In contrast, for AE-TO; when the dye is situated in the minor groove, the greatest changes in fluorescence occur for attachment via the quinoline moiety $\left(\mathrm{TO}_{\mathrm{Q} 6}\right)$ (Fig. S5, Table S8 $\dagger$ ). In terms of the base stacking environment, the weakest fluorescence enhancement was observed with TO adjacent to guanine bases (ODN4) as previously reported. ${ }^{18,33}$ The reason for this is not because the TO moiety is less fluorescent (i.e. strongly quenched) in this environment, but rather that the single stranded probe is poorly quenched (Fig. S5, Tables S8 and S10 $\dagger$ ). This could be due to strong single stranded stacking between TO and guanine bases. Attempts to reduce single stranded fluorescence $\left(F_{\mathrm{ss}}\right)$ of ODN4 by replacing guanine with inosine ${ }^{34}$ resulted in decreased $F_{\text {ss }}$ but unfortunately sequence specificity and duplex stabilisation were compromised (Fig. S19 and S20†).

\section{Duplex stabilisation by 2 '-O-methyl-RNA TO (2'-OMe-(ORNs)) probes with DNA and RNA targets}

An important application of fluorogenic oligonucleotide probes is detection of DNA and RNA in both live and fixed cells. ${ }^{35}$ A common approach is to use 2'-O-methyl oligoribonucleotide probes (2'-OMe-ORN) instead of DNA probes, as the former are much more stable in live cells, and the latter can also cause degradation of the target mRNA via the action of

\footnotetext{
$\$$ In this study the ratio of double to single stranded fluorescence $\left(F_{\mathrm{ds}} / F_{\mathrm{ss}}\right)$ was calculated on the basis of area under the fluorescence emission spectra from $510 \mathrm{~nm}$ to $650 \mathrm{~nm}$. More favourable $F_{\mathrm{ds}} / F_{\mathrm{ss}}$ values are obtained if a narrower band is selected, e.g. For ODN3 $\mathrm{C}_{6}-\mathrm{TO}_{\mathrm{B} 6}$ against its complementary DNA target between $510 \mathrm{~nm}$ and $555 \mathrm{~nm} F_{\mathrm{ds}} / F_{\mathrm{ss}}=7.7$ compared to 6.9 in the region $510 \mathrm{~nm}$ to $650 \mathrm{~nm}$, and in case of 2'-OMe-(ORN3) $\mathrm{AE}^{-\mathrm{TO}_{\mathrm{Q} 6}}$ against its complementary DNA target (discussed later) the relevant values are 43.9 compared to 33.9.
}

Table 2 Changes in melting temperature $\left(\Delta T_{m}\right)$ ODNs against RNA targets and $2^{\prime}-\mathrm{OMe}-(\mathrm{ORNs})$ against DNA and RNA targets. Conditions: see Table 1

\begin{tabular}{|c|c|c|c|c|c|c|}
\hline \multirow[b]{2}{*}{ Probe } & \multirow[b]{2}{*}{$\begin{array}{l}\text { Target } \\
\text { (matched) }\end{array}$} & \multicolumn{2}{|l|}{$\mathrm{X}=\mathrm{AE}$} & \multicolumn{2}{|c|}{$\mathrm{X}=\mathrm{C} 6$} & \multirow{2}{*}{$\begin{array}{l}\mathrm{X}=\mathrm{T} / \mathrm{U} \\
- \\
T_{\mathrm{m}}\end{array}$} \\
\hline & & $\begin{array}{l}\mathrm{TO}_{\mathrm{Q} 6} \\
\Delta T_{\mathrm{m}}{ }^{a}\end{array}$ & $\mathrm{TO}_{\mathrm{B} 6}$ & $\mathrm{TO}_{\mathrm{Q} 6}$ & $\mathrm{TO}_{\mathrm{B} 6}$ & \\
\hline ODN1 & RNA & 5.7 & $-^{b}$ & 3.3 & 8.2 & 35.9 \\
\hline ODN2 & & $-^{b}$ & $-^{b}$ & 1.3 & 5.2 & 32.0 \\
\hline ODN3 & & $-^{b}$ & $-^{b}$ & 0.6 & 5.9 & 48.9 \\
\hline ODN4 & & $-^{b}$ & $-^{b}$ & 0.8 & 6.3 & 44.6 \\
\hline 2'-OMe-(ORN1) & RNA & 7.8 & 7.7 & 4.7 & 7.4 & 42.6 \\
\hline $\begin{array}{l}\text { 2'-OMe-(5'- } \\
\text { GCAUXUUACG) }\end{array}$ & DNA & 18.0 & 19.3 & 9.7 & 14.3 & 25.2 \\
\hline 2'-OMe-(ORN2) & RNA & 6.2 & 4.9 & 0.2 & 0.7 & 44.6 \\
\hline $\begin{array}{l}2^{\prime} \text {-OMe-( } 5^{\prime}- \\
\text { GCAAXAUACG) }\end{array}$ & DNA & 10.3 & 8.8 & 4.3 & 6.8 & 35.8 \\
\hline 2'-OMe-(ORN3) & RNA & 4.0 & 4.8 & 0.5 & 4.6 & 60.1 \\
\hline $\begin{array}{l}\text { 2'-OMe-(5'- } \\
\text { GCACXCUACG) }\end{array}$ & DNA & 11.1 & 15.0 & 8.0 & 12.7 & 43.2 \\
\hline 2'-OMe-(ORN4) & RNA & 6.5 & 5.3 & 0.4 & 3.9 & 58.9 \\
\hline $\begin{array}{l}2^{\prime} \text {-OMe-(5'- } \\
\text { GCAGXGUACG) }\end{array}$ & DNA & 8.4 & 8.5 & 3.7 & 9.7 & 49.1 \\
\hline
\end{tabular}

endogenous RNase H. ${ }^{13,36}$ 2'-OMe probes have been used previously in combination with TO using a different design of the TO monomer. ${ }^{37}$ In order to elucidate the effects of the $2^{\prime}$-OMe modification on the properties of TO probes, 2 '-OMe probes (2'-OMe-(ORN1-4)) with the same sequences as ODN1-4, containing AE or C6 modifications, were synthesised and labelled with $\mathrm{TO}_{\mathrm{Q} 6}$ and $\mathrm{TO}_{\mathrm{B} 6}$. These probes were tested against both DNA and RNA targets (Table 2). Increases in melting temperature were greater against DNA than RNA, and the minor groove (AE) modification was superior to the major groove (C6). For $\mathrm{AE}$ there were no great differences between benzothiazole and quinoline attachment (Table 2, Fig. S15 and S16†). The highest increases in $T_{\mathrm{m}}$ were observed for 2'-OMe-(ORN1) with DNA targets $\left(\mathrm{AE}^{-\mathrm{TO}_{\mathrm{Q} 6}}+18.0{ }^{\circ} \mathrm{C}\right.$ and $\left.\mathrm{AE}-\mathrm{TO}_{\mathrm{B} 6}+19.3{ }^{\circ} \mathrm{C}\right)$. These increases are quite remarkable for a single intercalating fluorophore, and double labelled $2 \times \mathrm{AE}^{-\mathrm{TO}_{\mathrm{Q} 6}}$ provided even greater duplex stabilisation $\left(\Delta T_{\mathrm{m}}=+29.1{ }^{\circ} \mathrm{C}\right.$, Table $\left.\mathrm{S} 4 \dagger\right)$. Probes of this design with multiple TO insertions have great potential in duplex stabilisation and importantly are simple to synthesise. It is significant that the ability of 2'-OMe-(ORN1-4) to discriminate matched from mismatched DNA targets was preserved, and on average $\Delta T_{\mathrm{m}}$ was improved slightly in comparison to ODNs probes.

Next we examined the effect of mismatch position on $\Delta T_{\mathrm{m}}$ (i.e. $T_{\mathrm{m}}$ of duplex containing all Watson-Crick base pairs $-T_{\mathrm{m}}$ of duplex containing a single mismatch) by constructing five different DNA hybrids that gave a single mismatch against TO-2'-OMe-(ORN3) in various positions from -2 (2 bases to the 5 '-side of TO) to +2 ( 2 bases to the 3 '-side of TO) (Fig. 2, Table S7†). A similar study was performed by Okamoto with TO probes of a different chemical composition. ${ }^{38}$ For both 


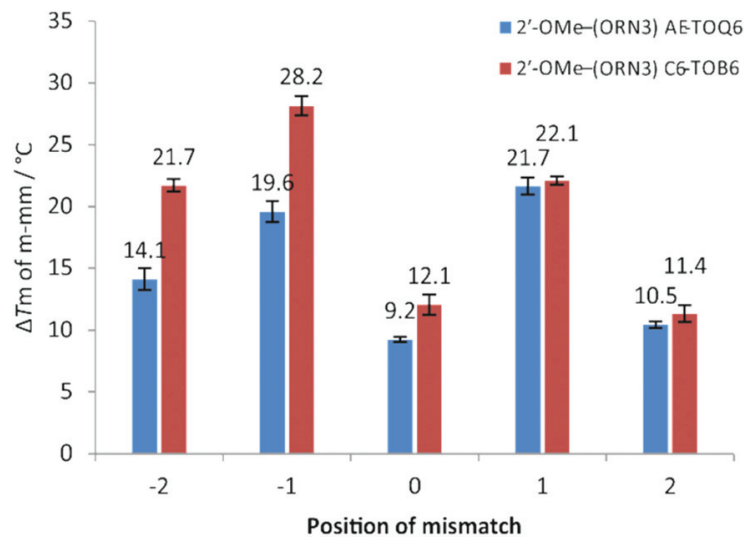

Fig. 2 UV melting for 2'-OMe-(ORN3) (2'-OMe-(5'-GCACXCUACG)) TO-modified oligonucleotides probes against various DNA targets. Position of mismatch refers to a mismatch in the target strand counting from the TO-modified base, e.g.: position "0" is directly opposite modification and " -2 " is two nucleobases towards $5^{\prime}$ end of the probe sequence. Number above bar $=\Delta T_{\mathrm{m}}$ to match target, $T_{\mathrm{m}}$ for fully matched targets $2^{\prime}$-OMe-(ORN3) AE-TO ${ }_{Q 6}: 51.7{ }^{\circ} \mathrm{C} ; 2^{\prime}$-OMe-(ORN3) C6-TO ${ }_{B 6}: 52.5^{\circ} \mathrm{C}$, all samples measured at $1.0 \mu \mathrm{M}$ with $1.1 \mathrm{eq}$. of target. Mismatch sequences see: Table S1, $†$ ODN3 - targets from -2 to +2 .

$\mathrm{AE}^{-} \mathrm{TO}_{\mathrm{Q} 6}$ and $\mathrm{C} 6-\mathrm{TO}_{\mathrm{B} 6}$ mismatch discrimination at positions -1 and +1 was excellent $\left(\Delta T_{\mathrm{m}}>20^{\circ} \mathrm{C}\right)$ and far superior to the case when the mispaired base is directly opposite TO $\left(\Delta T_{\mathrm{m}}=\right.$ 9-12 $\left.{ }^{\circ} \mathrm{C}\right)$. This position-dependence of mismatch discrimination is a critical consideration when designing TO probes to detect mutations or SNPs.

Fluorescence properties of 2'-OMe-(ORNs) probes against DNA and RNA targets

The 2'-OMe-(ORN1-4) series of probes show great potential as fluorogenic sensors of complementary DNA and RNA. The fluorescence enhancement upon duplex formation for $\mathrm{AE}^{-} \mathrm{TO}_{\mathrm{Q} 6}$ and $\mathrm{C6}-\mathrm{TO}_{\mathrm{B} 6}$ is excellent, and in the best cases much better than the equivalent deoxyribose (DNA) versions. The probes showed the same structural preference for dye orientation as the DNA probes; the most impressive fluorescence enhancement was observed for $\mathrm{AE}^{-\mathrm{TO}_{\mathrm{Q} 6}}$ and $\mathrm{C6}-\mathrm{TO}_{\mathrm{B} 6}$ against DNA targets. Limited duplex fluorescence was observed when the dye was attached in the alternative orientation $\left(\mathrm{AE}-\mathrm{TO}_{\mathrm{B} 6}\right.$ or C6- $\mathrm{TO}_{\mathrm{Q} 6}$, Fig. 3, Table 3). Surprisingly in one case $\left(\mathrm{AE}^{-\mathrm{TO}_{\mathrm{B} 6}}\right.$ in 2'-OMe-ORN4) the single stranded oligonucleotide was four times as fluorescent as its duplex with complementary DNA, and twice as fluorescent as its duplex with RNA. This sequence 2'-OMe-(5'-GCAGXGUACG) places the thiazole orange between guanine bases and it is likely that the resulting stacking interactions are sufficiently strong to allow the dye molecule to adopt a planar fluorescent conformation. The same effect is observed with the equivalent DNA probe $\left(\mathrm{AE}-\mathrm{TO}_{\mathrm{B} 6}\right.$ in ODN4, Fig. $\mathrm{S} 12 \dagger)$ but to a smaller extent, and it is unclear why in this single case the 2 '-O-methyl sugars promote fluorescence in the single strand whereas in other cases they suppress it. Nevertheless this result shows the importance of evaluating different modes of attachment between TO and DNA/RNA. The C6-TO ${ }_{\mathrm{B} 6}$ modification in 2'-O-methyl RNA gave good $F_{\mathrm{ds}} / F_{\mathrm{ss}}$ ratios with DNA targets, for example 2'-OMe-(ORN3) and 2'OMe-(ORN1) gave fluorescence enhancements of 17-fold and 15-fold respectively (Fig. 4 and S22 $\dagger$ ). Somewhat smaller increases were observed with RNA targets. With complementary DNA targets, the $\mathrm{AE}^{-} \mathrm{TO}_{\mathrm{Q} 6}$ modification attached to 2'OMe-(ORN3) gave an impressive 34-fold enhancement (Fig. 4) (44-fold if calculated in the 510-555 $\mathrm{nm}$ range), and when attached to 2'-OMe-(ORN1) the enhancement was 22-fold (27-fold for the 510-555 $\mathrm{nm}$ range). For double TO-labelled probes, $F_{\mathrm{ds}} / F_{\mathrm{SS}}$ of $2 \times \mathrm{AE}^{-T O} \mathrm{Q}_{\mathrm{Q} 6} 2$-OMe-(ORN1) was reduced to 14-fold (Table S9†) which may be due to mutual quenching of TO dyes in the double strand. ${ }^{14}$ However, we have only so far studied a single example of dual-labelled TO probes, and it may be possible to optimise the design to improve their fluorescent properties.

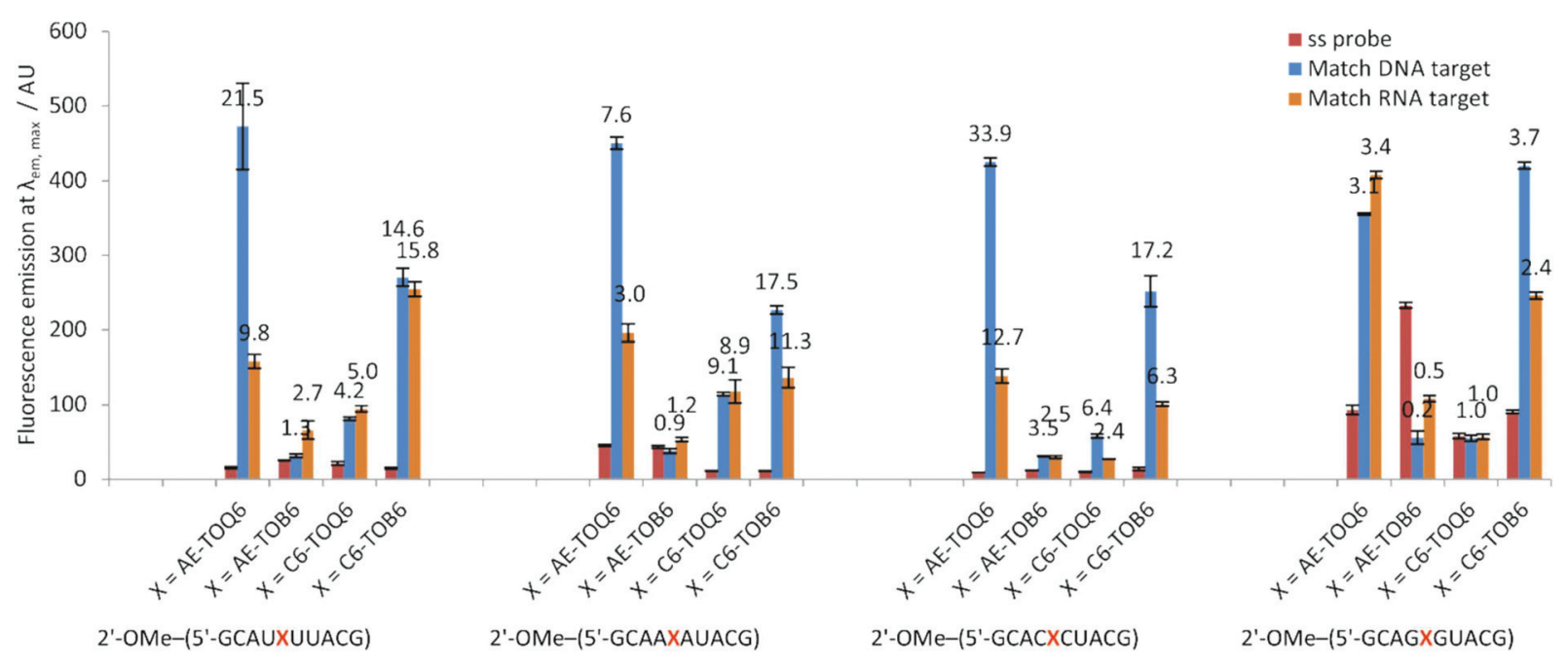

Fig. 3 Fluorescence emission intensities at $\lambda_{\mathrm{em}}$, max of a single stranded 2'-OMe-(ORN1-4) probes and DNA and RNA matched targets duplexes. Conditions: see Table 1. 
Table 3 Changes in fluorescence emission $\left(F_{\mathrm{ds}} / F_{\mathrm{ss}}\right)$ for 2'-OMe-(ORN1-4) with DNA targets before and after formation of matched and mismatched duplexes. Conditions: see Table 1. In this study $F_{\mathrm{ds}} / F_{\mathrm{ss}}$ was calculated on the basis of area under the fluorescence emission spectra from $510 \mathrm{~nm}$ to $650 \mathrm{~nm}$. More favourable values are obtained if a narrower band in the emission spectra is selected, e.g. For 2'-OMe-(ORN3) AE-TO ${ }_{Q 6}$ against its complementary DNA target between $510 \mathrm{~nm}$ and $555 \mathrm{~nm} ; F_{\mathrm{ds}} / F_{\mathrm{ss}}=43.9$ compared to 33.9 integrated in the region from $510 \mathrm{~nm}$ to $650 \mathrm{~nm}$

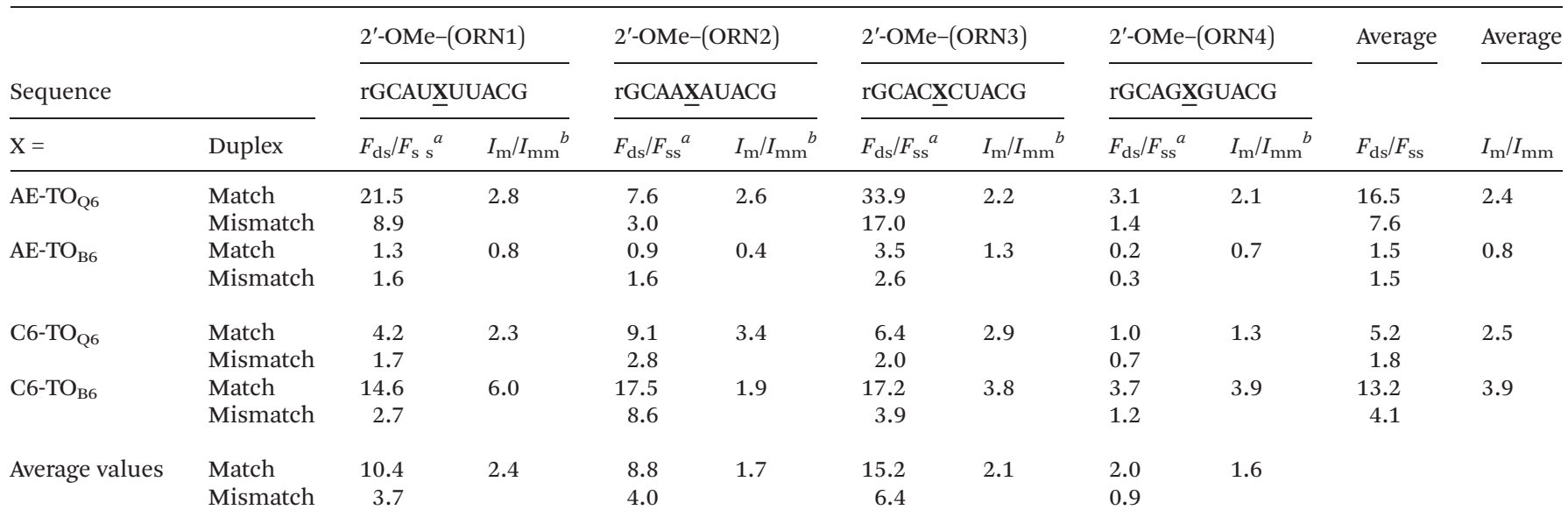

${ }^{a}$ Ratio of integrated fluorescence intensity for $F_{\mathrm{ds}}$ and $F_{\mathrm{ss}}$ of $2^{\prime}$-OMe-(ORN) probe with matched or mismatched target. ${ }^{b}$ Ratio of fluorescence intensity of matched $\left(I_{\mathrm{m}}\right)$ and mismatched $\left(I_{\mathrm{mm}}\right)$ intensity at $\lambda_{\mathrm{em}}$ max.
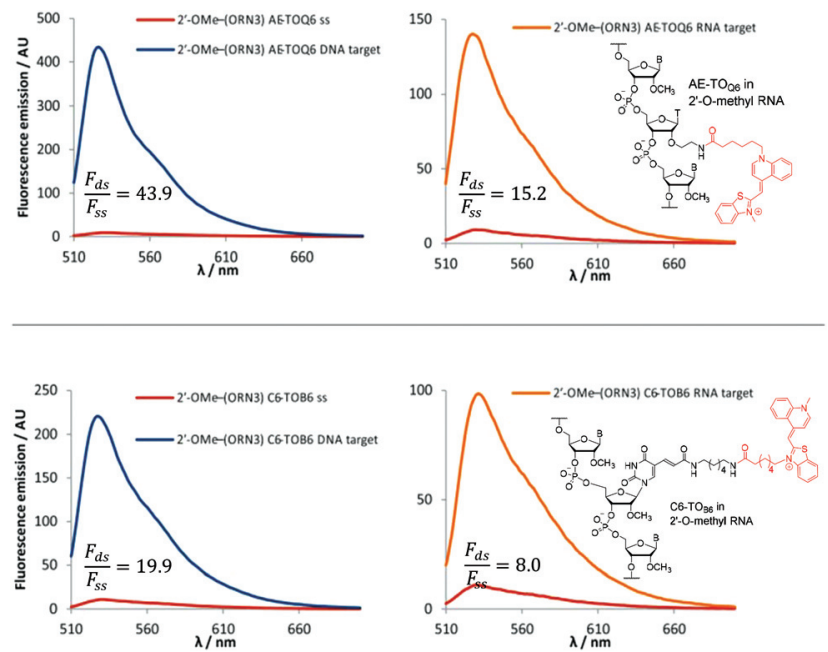

Fig. 4 Examples of fluorescence emission spectra of single stranded (ss) probes and DNA or RNA matched target duplexes. Probes: 2'-OMe(ORN3) (5'-GCACXCUACG) were $\mathrm{X}=\mathrm{AE}-\mathrm{TO}_{\mathrm{Q} 6}$ or $\mathrm{C} 6-\mathrm{TO}_{\mathrm{B} 6}$ with structures of modification and TO isomer with optimum fluorescence. Examples of $F_{\mathrm{ds}} / F_{\mathrm{ss}}$ are calculated in range $510-555 \mathrm{~nm}$. Conditions: see Table 1.

Fluorescence quantum yields of $\mathrm{AE}^{-\mathrm{TO}_{\mathrm{Q} 6}}$ of 2'-OMe-(ORN3) and 2 '-OMe-(ORN1) were 0.318 and 0.580 respectively against DNA targets (Table 4). ${ }^{39}$ This pleasingly high fluorescence enhancement is in part due to the low background fluorescence observed in the single stranded 2'-OMe RNA TO-oligonucleotides ( $\Phi=0.013-0.022,2$ '-OMe-(ORN1) and 2'-OMe(ORN3)) in comparison to equivalent ODN probes $(\Phi=$ 0.050-0.089, Table 4). This puts our simplified design on par with other TO probe systems. ${ }^{13,15}$ If a mispaired base is positioned opposite to TO, discrimination on the basis of fluo-
Table 4 Fluorescence quantum yields of ODN1 (5'-GCATXTTACG), ODN3 (5'-GCACXCTACG), 2'-OMe-(ORN1) (2'-OMe-(5'-GCAUXUUACG)) and 2'-OMe-(ORN3) (2'-OMe-(5'-GCACXCUACG)) oligonucleotides probes with matched DNA and RNA targets. Samples were measured at $\lambda_{\mathrm{ex}}=484 \mathrm{~nm}, \lambda_{\mathrm{em}}=490 \mathrm{~nm}$, ex slit width $=3 \mathrm{~nm}$, em slit width $=3 \mathrm{~nm}$, $20^{\circ} \mathrm{C}$. Reference dye: fluorescein in $0.1 \mathrm{M} \mathrm{NaOH}$

\begin{tabular}{|c|c|c|c|c|c|c|}
\hline & \multicolumn{5}{|l|}{$\Phi$} \\
\hline & & ss & DNA & RNA & DNA/ss & RNA/ss \\
\hline \multirow{4}{*}{ ODN1 } & $\mathrm{AE}-\mathrm{TO}_{\mathrm{Q} 6}$ & 0.089 & 0.279 & 0.278 & 3.1 & 3.1 \\
\hline & $\mathrm{AE}-\mathrm{TO}_{\mathrm{B} 6}$ & 0.054 & 0.067 & 0.172 & 1.2 & 3.2 \\
\hline & $\mathrm{C} 6-\mathrm{TO}_{\mathrm{Q} 6}$ & 0.115 & 0.118 & 0.208 & 1.0 & 1.8 \\
\hline & $\mathrm{C} 6-\mathrm{TO}_{\mathrm{B} 6}$ & 0.056 & 0.469 & 0.477 & 8.4 & 8.5 \\
\hline \multirow[t]{4}{*}{ 2'-OMe-(ORN1) } & $\mathrm{AE}-\mathrm{TO}_{\mathrm{Q} 6}$ & 0.016 & 0.580 & 0.215 & 36.3 & 13.4 \\
\hline & $\mathrm{AE}-\mathrm{TO}_{\mathrm{B} 6}$ & 0.035 & 0.065 & 0.113 & 1.9 & 3.2 \\
\hline & $\mathrm{C} 6-\mathrm{TO}_{\mathrm{Q}}$ & 0.023 & 0.152 & 0.147 & 6.6 & 6.4 \\
\hline & $\mathrm{C} 6-\mathrm{TO}_{\mathrm{B} 6}$ & 0.019 & 0.493 & 0.477 & 25.9 & 25.1 \\
\hline \multirow[t]{4}{*}{ ODN3 } & $\mathrm{AE}-\mathrm{TO}_{\mathrm{Q} 6}$ & 0.051 & 0.061 & 0.043 & 1.2 & 0.8 \\
\hline & $\mathrm{AE}-\mathrm{TO}_{\mathrm{B} 6}$ & 0.034 & 0.053 & 0.062 & 1.6 & 1.8 \\
\hline & $\mathrm{C} 6-\mathrm{TO}_{\mathrm{Q}}$ & 0.036 & 0.045 & 0.050 & 1.3 & 1.4 \\
\hline & $\mathrm{C} 6-\mathrm{TO}_{\mathrm{B} 6}$ & 0.050 & 0.073 & 0.063 & 1.5 & 1.3 \\
\hline \multirow[t]{4}{*}{ 2'-OMe-(ORN3) } & $\mathrm{AE}-\mathrm{TO}_{\mathrm{Q} 6}$ & 0.013 & 0.318 & 0.162 & 24.6 & 12.5 \\
\hline & $\mathrm{AE}-\mathrm{TO}_{\mathrm{B} 6}$ & 0.013 & 0.086 & 0.035 & 6.9 & 2.7 \\
\hline & $\mathrm{C} 6-\mathrm{TO}_{\mathrm{O} 6}$ & 0.014 & 0.096 & 0.044 & 7.1 & 3.1 \\
\hline & C6-TO ${ }_{\mathrm{B} 6}$ & 0.022 & 0.382 & 0.190 & 17.3 & 8.6 \\
\hline
\end{tabular}

rescence intensity ( $\left.I_{\text {matched }} / I_{\text {mismatched }}\right)$ of 2'-O-methyl RNA TO probes against DNA targets is significant, e.g. for $2^{\prime}-\mathrm{OMe}-$ (ORN1) and 2'-OMe-(ORN3) with $\mathrm{C} 6-\mathrm{TO}_{\mathrm{B} 6}, 6.0$ and 3.8-fold differences respectively were observed, whereas for ODN1 and ODN3 probes, the corresponding differences were 3.3 and 2.8fold. Varying the mismatch position relative to thiazole orange in the 2 '-OMe-(ORN3) sequence gave significant fluorescence discrimination at positions -1 and +1 (3.4 to 3.6-fold for $\mathrm{C}_{6}$ - 
$\mathrm{TO}_{\mathrm{B} 6}$ and 2.0 to 2.4 for $\left.\mathrm{AE}-\mathrm{TO}_{\mathrm{Q}}\right)$, i.e. the positions at which mismatch discrimination by $T_{\mathrm{m}}$ is maximum (Fig. $\mathrm{S} 21 \dagger$ ). With further development, the favourable fluorescence properties of these simple 2'-OMe TO probes may prove useful in detection of DNA in cells.

\section{Effect of linker length on the properties of 2'-OMe-(ORN1) AE-TO probes}

As shown above, the properties of the TO probes are somewhat altered when they are attached to the 5-position of the nucleobase by different linkers (C6 or PA) presumably due to differences in linker length. We also explored the effects of the length of the linker between the TO and the 2'-position of the sugar (AE modification). For this study $\mathrm{TO}_{\mathrm{B} 10}$ and $\mathrm{TO}_{\mathrm{Q} 10}$ NHS esters were synthesized and used to label the 2'-OMe-(ORN1) AE and C6 probes (Table S2 $\dagger$ ). UV melting studies with fully matched DNA and RNA targets showed the same trends as previously observed for $\mathrm{AE}$ and $\mathrm{C} 6-\mathrm{TO}_{\mathrm{B} 6 / \mathrm{Q} 6}$ with slightly lower increases in $T_{\mathrm{m}}$ (Fig. S18 $\dagger$ ). The fluorescence changes also followed the same trends as the $\mathrm{C} 6$ and AE versions against DNA and RNA targets, but with no advantage over the shorter linker (Fig. S17†). Fluorescence-based mismatch discrimination was compromised, and taking the above results into account there is no advantage to be gained by increasing linker length from 6 to 10 atoms.

Circular dichroism spectroscopy of the modified TO-containing DNA duplexes (TO-ODNs) indicated in general the formation of B-like DNA with no major perturbation from the unmodified structures (Fig. S27B, S28 and S30†). CD spectra of the 2 '-OMe-(ORN) duplexes are very similar to the equivalent unmodified duplexes (Fig. S27A, S29 and S31†).

\section{Conclusions}

In summary, we have synthesised a range of thiazole orange (TO) probes in which $\mathrm{TO}$ is attached to the nucleobase or sugar of a thymidine nucleotide using various linkers. The properties of duplexes between TO-probes and their DNA and RNA targets depend on the length of the linker between TO and the oligonucleotide, the position of attachment of thiazole orange to the nucleotide (nucleobase - major groove or sugarminor groove) and the position of attachment of the linker to thiazole orange (via the benzothiazole or quinoline moiety). Attachment of thiazole orange via its benzothiazole moiety to the major groove of oligonucleotides $\left(\mathrm{C6}-\mathrm{TO}_{\mathrm{B} 6}\right)$ and via the quinoline moiety in the minor groove $\left(\mathrm{AE}-\mathrm{TO}_{\mathrm{Q}}\right)$ provides significant fluorescence enhancement on duplex formation with DNA or RNA targets. Duplex melting experiments showed higher stabilisation by $\mathrm{C}^{-}-\mathrm{TO}_{\mathrm{B} 6}$ than $\mathrm{C6}-\mathrm{TO}_{\mathrm{Q}}$ whereas the $\mathrm{AE}$ modification showed similar effects for B6 and Q6 attachment. Preliminary experiments with double labelled 2'-OMe RNA $(2 \times$

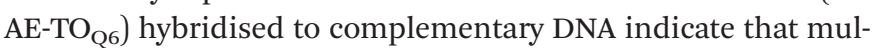
tiple additions of TO can provide significantly enhanced duplex stability. However, the effects of multiple TO insertions on sequence specificity in a genomic context remain to be investigated. For both $\mathrm{AE}^{-\mathrm{TO}_{\mathrm{Q} 6}}$ and $\mathrm{C} 6-\mathrm{TO}_{\mathrm{B} 6}$ modifications, as previously described in different systems, ${ }^{18}$ mismatch discrimination against DNA targets at positions -1 and +1 was excellent and far superior to the case when the mispaired base is directly opposite TO. This is a crucial consideration when designing TO probes to detect mutations or SNPs. Similar effects were observed previously in other TO probe configurations. $^{38}$ The fluorogenic properties of DNA TO-probes are limited by residual fluorescence in the single stranded state due to the cationic TO interacting with anionic DNA, causing single stranded TO-probes to adopt stable secondary structures in which the dye is fluorescent. This has been addressed previously by the use of PNA probes and ECHO probes. Here we confirm that 2'-O-Me RNA probes also reduce the background fluorescence $^{15}$ whilst maintaining simplicity of design and convenience of synthesis. Anomalous fluorescence results were obtained when $\mathrm{TO}$ in an $\mathrm{AE}^{-\mathrm{TO}_{\mathrm{Q} 6}}$ context is placed between two guanine bases and this highlights the importance of studying the system in detail. In conclusion, the 2'-OMe-RNA TO-probes presented here have potential for applications in cell imaging of DNA and RNA and warrant further investigation, particularly in FRET systems in combination with other fluorophores.

\section{Conflicts of interest}

There are no conflicts of interest to declare.

\section{Acknowledgements}

This work was supported by the Marie Skłodowska-Curie Innovative Training Network (ITN) ClickGene (H2020MSCA-ITN-2014-642023) and UK BBSRC grant BB/J001694/2 (extending the boundaries of nucleic acid chemistry) and $\mathrm{BB} /$ R008655/1.

\section{Notes and references}

1 J. Nygren, N. Svanvik and M. Kubista, Biopolymers, 1998, 46, 39-51.

2 J. Bunkenborg, N. I. Gadjev, T. Deligeorgiev and J. P. Jacobsen, Bioconjugate Chem., 2000, 11, 861-867.

3 F. Hovelmann and O. Seitz, Acc. Chem. Res., 2016, 49, 714723.

4 L. Bethge, I. Singh and O. Seitz, Org. Biomol. Chem., 2010, 8, 2439-2448.

5 I. Oomoto, A. Suzuki-Hirano, H. Umeshima, Y. W. Han, H. Yanagisawa, P. Carlton, Y. Harada, M. Kengaku, A. Okamoto, T. Shimogori and D. O. Wang, Nucleic Acids Res., 2015, 43, e126.

6 Q. Lu, Z. Zhou, Y. Mei, W. Wei and S. Liu, Talanta, 2013, 116, 958-963. 
7 R. Lartia and U. Asseline, Chem. - Eur. J., 2006, 12, $2270-$ 2281.

8 M. Segal, E. Yavin, P. Kafri, Y. Shav-Tal and B. Fischer, J. Med. Chem., 2013, 56, 4860-4869.

9 S. Berndl and H. A. Wagenknecht, Angew. Chem., Int. Ed., 2009, 48, 2418-2421.

10 S. Berndl, S. D. Dimitrov, F. Menacher, T. Fiebig and H.-A. Wagenknecht, Chem. - Eur. J., 2016, 22, 2386-2395.

11 Y. Kimura, T. Hanami, Y. Tanaka, M. J. L. de Hoon, T. Soma, M. Harbers, A. Lezhava, Y. Hayashizaki and K. Usui, Biochemistry, 2012, 51, 6056-6067.

12 E. Socher, L. Bethge, A. Knoll, N. Jungnick, A. Herrmann and O. Seitz, Angew. Chem., Int. Ed., 2008, 47, 9555-9559.

13 F. Hövelmann, I. Gaspar, J. Chamiolo, M. Kasper, J. Steffen, A. Ephrussi and O. Seitz, Chem. Sci., 2016, 7, 128-135.

14 F. Hövelmann, I. Gaspar, A. Ephrussi and O. Seitz, J. Am. Chem. Soc., 2013, 135, 19025-19032.

15 T. Kubota, S. Ikeda, H. Yanagisawa, M. Yuki and A. Okamoto, Bioconjugate Chem., 2009, 20, 1256-1261.

16 O. Köhler, D. V. Jarikote and O. Seitz, ChemBioChem, 2005, 6, 69-77.

17 J. Qiu, A. Wilson, A. H. El-Sagheer and T. Brown, Nucleic Acids Res., 2016, 44, e138.

18 S. Ikeda, T. Kubota, K. Kino and A. Okamoto, Bioconjugate Chem., 2008, 19, 1719-1725.

19 P. L. Southwick, L. A. Ernst, E. W. Tauriello, S. R. Parker, R. B. Mujumdar, S. R. Mujumdar, H. A. Clever and A. S. Waggoner, Cytometry, 1990, 11, 418-430.

20 D. V. Jarikote, O. Köhler, E. Socher and O. Seitz, Eur. J. Org. Chem., 2005, 3187-3195.

21 Y. Xia, R. Zhang, Z. Wang, J. Tian and X. Chen, Chem. Soc. Rev., 2017, 46, 2824-2843.

22 I. Gaspar, F. Hövelmann, J. Chamiolo, A. Ephrussi and O. Seitz, ACS Chem. Biol., 2018, 13, 742-749.
23 E. Privat, T. Melvin, F. Merola, G. Schweizer, S. Prodhomme, U. Asseline and P. Vigny, Photochem. Photobiol., 2002, 75, 201-210.

24 J. Booth, T. Brown, S. J. Vadhia, O. Lack, W. J. Cummins, J. O. Trent and A. N. Lane, Biochemistry, 2005, 44, 4710-4719.

25 M. J. J. Blommers, F. Natt, W. Jahnke and B. Cuenoud, Biochemistry, 1998, 37, 17714-17725.

26 S. Sindbert, S. Kalinin, H. Nguyen, A. Kienzler, L. Clima, W. Bannwarth, B. Appel, S. Muller and C. A. Seidel, J. Am. Chem. Soc., 2011, 133, 2463-2480.

27 B. Cuenoud, F. Casset, D. Hüsken, F. Natt, R. M. Wolf, K.-H. Altmann, P. Martin and H. E. Moser, Angew. Chem., Int. Ed., 1998, 37, 1288-1291.

28 J. Bijapur, S. Bergqvist, T. Brown, M. D. Keppler and K. R. Fox, Nucleic Acids Res., 1999, 27, 1802-1809.

29 D. V. Jarikote, O. Kohler, E. Socher and O. Seitz, Eur. J. Org. Chem., 2005, 3187-3195.

30 S. Ikeda, T. Kubota, K. Kino and A. Okamoto, Bioconjugate Chem., 2008, 19, 1719-1725.

31 R. B. Mujumdar, L. A. Ernst, S. R. Mujumdar, C. J. Lewis and A. S. Waggoner, Bioconjugate. Chem., 1993, 4, 105-111.

32 O. Köhler and O. Seitz, Chem. Commun., 2003, 2938-2939.

33 D. V. Jarikote, N. Krebs, S. Tannert, B. Röder and O. Seitz, Chem. - Eur. J., 2007, 13, 300-310.

34 A. Okamoto, Chem. Soc. Rev., 2011, 40, 5815-5828.

35 T. Kubota, S. Ikeda, H. Yanagisawa, M. Yuki and A. Okamoto, Bioconjugate Chem., 2009, 20, 1256-1261.

36 T. L. Fisher, T. Terhorst, X. D. Cao and R. W. Wagner, Nucleic Acids Res., 1993, 21, 3857-3865.

37 F. Hövelmann, I. Gaspar, S. Loibl, E. A. Ermilov, B. Röder, J. Wengel, A. Ephrussi and O. Seitz, Angew. Chem., Int. Ed., 2014, 53, 11370-11375.

38 K. Sugizaki and A. Okamoto, Bioconjugate. Chem., 2010, 21, 2276-2281.

39 A. M. Brouwer, Pure Appl. Chem., 2011, 83, 2213. 